\title{
A Legitimidade da Intervenção Estatal na Publicidade de Produtos Sujeitos à Vigilância Sanitária
}

\author{
THE LEGITIMACY OF STATE INTERVENTION IN THE ADVERTISING OF \\ PRODUCTS SUBJECT TO HEALTH SURVEILLANCE
}

\author{
Erika Mattos da Veiga ${ }^{(*)}$ \\ Maria Inês Moron Pannunzio(**) \\ Thiago Rocha da Cunha ${ }^{(* * *)}$ \\ Volnei Garrafa ${ }^{(* * * *)}$
}

\section{RESUMO}

O presente estudo buscou analisar o papel ético do Estado Brasileiro, via Agência Nacional de Vigilância Sanitária, em intervir na publicidade de produtos que possam causar impactos negativos na saúde da população. A partir dos referenciais da Bioética de Intervenção - perspectiva utilitarista crítica e solidária que considera as relações sociais de produção e as interrelações humanas, atribuindo ao Estado o papel de protetor dos interesses de indivíduos que se encontrem em condições de vulnerabilidade - foi realizada uma análise da ideologia de mercado que sustenta um discurso contrário à intervenção pública. O estudo tomou como referência cinco casos emblemáticos relacionados ao tema: produtos fumígeros, bebidas alcoólicas, medicamentos, alimentos em geral e alimentos para crianças. Como metodologia foi utilizada a hermenêutica legislativa do ordenamento jurídico

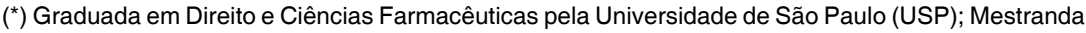
em Bioética pela Universidade de Brasília (UNB). Assistente do Núcleo de Assessoramento em Assuntos Internacionais da Agência Nacional de Vigilância Sanitária (ANVISA). Brasília/DF, Brasil. E-mail: <erika.veiga@anvisa.gov.br>.

$\left.{ }^{(* *}\right)$ Licenciada em Filosofia pela USP; Mestre em Educação, Arte e História da Cultura pelo Instituto Mackenzie. Coordenadora do Setor Educativo do Museu de Arte Contemporânea de Sorocaba. Sorocaba/SP, Brasil. E-mail: <inespan@gmail.com>.

${ }^{* * *}$ Bacharel em Biomedicina pelo Centro Universitário de Votuporanga; Mestrando em Bioética pela Universidade de Brasília (UnB). Brasília/DF, Brasil. E-mail: <thiagocunha@unb.br>.

$\left({ }^{* * * *}\right)$ Pós-Doutor em Bioética pela Universidade La Sapienza, Roma/ltália; Cátedra UNESCO de Bioética da Faculdade de Ciências da Saúde, UnB. Brasília/DF, Brasil. E-mail: <volnei@ unb.br>. Texto recebido em 08.07.10. Revisado em 04.11.10. Aprovado em 04.03.11. 
do País, relacionando os dados obtidos com o objeto da presente investigação: a intervenção ou não do Estado na publicidade de produtos sujeitos à vigilância. A pesquisa permitiu concluir que a intervenção estatal é legitima no sentido de proteger a população usuária, que é sempre vulnerável nesta relação unilateral de consumo.

\section{Palavras-chave:}

Bioética; Intervenção Estatal; Produtos de Consumo; Publicidade; Vigilância Sanitária.

\section{ABSTRACT}

This essay aims at analysing the ethical role of the State, through the National Health Surveillance Agency (Anvisa), in regulating the advertisement of products that may negatively impact on the population's health. From the references of Intervention Bioethics - utilitarian perspective that considers critical and supportive social relations of production and the inter-human relations giving the state the role of protector of the interests of individuals who are in conditions of vulnerability - was performed an analysis of the market ideology that sustains a speech contrary to public policy. The present work focuses on six emblematic cases related to the matter: smoking products, alcoholic beverage, medicines, food for lactant women, food in general and food for children. It presents an analysis of the free market ideology that backs the argument against public intervention. The methodology used in this inquiry is the interpretation of legal texts, which corresponds to interpreting the country's legal framework, linking the obtained data with the object of the actual work: state intervention (or non-intervention) in the advertisement of products subject to surveillance. The essay concludes that state intervention is legitimate when aimed at protecting users, who are always vulnerable in this unilateral consumer relationship.

\section{Keywords:}

Advertisement; Bioethics; Consumption Products; Health Surveillance; State Intervention.

\section{INTRODUÇÃO}

O controle da publicidade de produtos consumidos pela população tem gerado profundas discussões no Brasil. Se, por um lado, por intermédio 
de seus organismos reguladores, o Estado tem a obrigação de proteger a população usuária, por outro, as empresas produtoras preferem a liberdade de ação por meio de mecanismos de autorregulação.

Em maio de 2007, o Conselho Nacional de Autorregulamentação Publicitária (Conar) e as associações e federações ligadas ao setor lançaram um manifesto endereçado às autoridades e ao mercado publicitário, questionando a competência da Agência Nacional de Vigilância Sanitária (Anvisa), organismo do Ministério da Saúde, para legislar sobre publicidade de produtos sob sua responsabilidade ${ }^{(1)}$.

O objetivo do presente estudo foi realizar uma reflexão ética sobre a intervenção do Estado, por intermédio da Anvisa, na divulgação de produtos sujeitos à vigilância sanitária, bem como julgar se há legitimidade ou não nessa atuação.

\section{BREVE REVISÃO DA LITERATURA}

O Código Brasileiro de Autorregulamentação Publicitária define publicidade e propaganda como "atividades destinadas a estimular o consumo de bens e serviços, bem como promover instituições, conceitos ou ideias" (2). Essa atividade é regulada em vários países. Na União Europeia, a publicidade de tabaco é proibida na televisão, no rádio e na internet; no Brasil, manifestações esportivas e culturais não podem ser patrocinadas por empresas desse ramo; na Suécia, a publicidade dirigida às crianças é estritamente regulamentada e, até mesmo, proibida na televisão(3)(4).

Recentemente, vêm aumentando as pressões da sociedade civil organizada contra abusos da publicidade. Cientistas britânicos iniciaram recentemente uma campanha contra as publicidades enganosas, com a alegação de que certos anúncios adotam linguagens que, para o leigo, parece técnicas, mas, na verdade, não passam de discurso pseudocientífico ${ }^{(5)}$.

Dora Porto, coautora da proposta inicial da Bioética de Intervenção, considera, a propósito, que vem ocorrendo massificação da informação no

(1) ABA, ABAP, ABERT, ABTA, ANER, ANJ, CENTRAL DE OUTDOOR, FENAPRO, FENEEC, IAB Anvisa não é competente para legislar sobre publicidade. Disponível em: <http://www.conar.org.br/

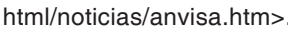

(2) CONAR. Código Nacional de Autorregulamentação Publicitária. Disponível em: <http:// www.conar.org.br/html/codigos/todos\%20os\%20capitulos.htm>.

(3) Corrigendum to Directive 2003/33/EC of the European Parliament and of the Council of 26 May 2003 on the approximation of the laws, regulations and administrative provisions of the Member States relating to the advertising and sponsorship of tobacco products. Aberdeen, Official Journal of the European Union, 152, 2003. p.16-19.

(4) SADER, Emir. O exemplo da democracia sueca. Agência Carta Maior 2004. Disponível em: $<$ www.agenciacartamaior.com.br>. Acesso em: 22 nov. 2007.

(5) CIENTISTAS põem anúncios em xeque. Valor Econômico, São Paulo, 20 jan. 2007. p. B5. 
seio da sociedade mundial graças à tecnologia de comunicação, na medida em que a televisão e a internet atuam como fortes articuladoras tanto do consumo, quanto da ideologia do consumo ${ }^{(6)}$. A publicidade comercial divulga produtos para o consumidor e, subjacente à simples divulgação, existe uma intenção ideológica, onde o indivíduo não só é conduzido a consumir, mas também a assumir determinadas convicções.

As previsões sobre o fim das ideologias não se realizaram e o conceito apresenta novas definições, manifesta Bauman ${ }^{(7)}$, para quem a ideologia de mercado é perniciosa na proporção em que estimula os indivíduos a encontrar soluções individuais para problemas coletivos. A união de forças para a solidariedade e responsabilidade social se torna desnecessária, uma vez que a ideologia baseada no consumo permite a reprodução do modus operandi da sociedade na dimensão individual, unicamente pela satisfação do consumidor. Esse processo rompe o tecido social e impede o surgimento de dinâmicas coletivas, dificultando a transformação da estrutura simbólica e do comportamento a ela associado.

No século 20, os indivíduos passaram a ser identificados por seus hábitos de consumo. Atualmente, a publicidade fixa nos produtos signos e imagens de beleza, sedução, autorrealização e qualidade de vida, tornando as mercadorias verdadeiras ilusões que fascinam o consumidor. A ideia é que as mercadorias venham a ser adquiridas independentemente de seu valor de uso, gerando um consumo que muitas vezes privilegia a inutilidade ${ }^{(8)}$.

A publicidade passa a ter, então, valor ideológico, compensatório, pedagógico, tornando-se referência, ensinando o que e como consumir. Nesse sentido, Baudrillard(9) afirma que consumo é uma imposição moral, um sistema de valores com a função de integração grupal e controle social. A indústria cultural e o fenômeno do consumismo promovem a massificação da sociedade, na qual os indivíduos aderem à banalização da vida cotidiana.

Segundo Eagleton ${ }^{(10)}$, o termo ideologia pode revelar a determinação social do pensamento, por meio de falsas ideias do interesse de uma classe dominante. Os signos, significados e valores, que colaboram na reprodução de um valor social, têm sentido pejorativo, mas também podem ser neutros, quando denotam uma conjuntura significante entre discurso e interesses políticos. As ideologias utilizam dispositivos de unificação, como a naturalização, a ilusão e a racionalização, mas não são universais, pois não têm características invariáveis. Todas têm um âmago de verdade, mas, isoladamente, são parciais e falhas.

(6) PORTO, Dora. Tecnologia \& ideologia: os dois lados da moeda que produz vulnerabilidade. Revista Brasileira de Bioética, Brasília, v. 2, n.1, p. 63-86, 2006.

(7) BAUMAN, Zygmunt. [Artigo publicado no jornal] La Repubblica, 16 set. 2007.

(8) VESTERGAARD, Torben; SCHRODER Kim. A linguagem da propaganda. 4. ed. São Paulo: Martins Fontes, 2004. 274 p.

(9) BAUDRILLARD, JEAN. A sociedade do consumo. 2. ed. Lisboa: Edições 70, 2007. 216 p.

(10) EAGLETON, Terry. Ideologia: uma introdução. São Paulo: UNESP, 1997. 204 p. 
A visão sociológica de que a ideologia seria o "cimento" de uma formação social ou o "mapa cognitivo" que orienta as ações torna-se despolitizadora, já que esvazia o conceito de ideologia dos conflitos e contradições. A ideologia não é, como defende o materialismo histórico, o princípio fundador da unidade social, mas tenta reconstruir essa unidade em nível imaginário. É uma força social organizadora que constitui sujeitos na sua experiência vivida e equipa-os com valores para suas tarefas sociais e para a reprodução da ordem social. Os efeitos ideológicos são gerados por instituições, pelo mercado, por processos políticos impessoais que, muitas vezes, não levam em consideração a subjetividade do sujeito.

A saída, então, seria viabilizar uma prática reflexiva, levando ao esclarecimento de todo esse processo, o que possibilitaria a libertação das crenças e ideologias impostas.

A bioética - uma nova disciplina do campo das éticas aplicadas procura, por meio da discussão e deliberação sobre questões práticas, orientar as ações racionais e morais no campo da saúde. Garrafa e Porto(11)(12)(13), autores da proposta conhecida por Bioética de Intervenção $(\mathrm{BI})$, expressaram a necessidade de uma abordagem teórica politizada que busca soluções viáveis para os conflitos localmente identificados, considerando o contexto e os fatores que lhes dão origem para, então, defender os direitos das populações excluídas do processo de desenvolvimento econômico e social.

Dados os antecedentes da ideologia que sustenta a publicidade em sociedades de consumo, a escolha desse referencial teórico caracteriza o posicionamento crítico a que se propõe este artigo.

\section{METODOLOGIA}

A metodologia fará a revisão da literatura afeta ao tema, acompanhada da hermenêutica jurídica dos preceitos legislativos a ele relacionados: Constituição Federal, Código de Defesa do Consumidor e o Estatuto da Criança e do Adolescente, além da pertinente legislação sanitária. Segundo Carlos Maximiliano (1980, p. 1) ${ }^{(14)}$, a hermenêutica jurídica é a teoria científica que tem por objeto "o estudo e a sistematização dos processos aplicáveis para determinar o sentido e o alcance das expressões do direito". Consiste, portanto, na interpretação do ordenamento jurídico, de modo a relacioná-lo

(11) GARRAFA, Volnei; PORTO, Dora. Intervention bioethics: a proposal for peripheral countries in a context f power and injustice. Bioethics, Diliman, v. 17, n. 5-6, p. 399-415, 2003.

(12) PORTO, Dora; GARRAFA Volnei. Bioética de Intervenção: considerações sobre a economia de mercado. Bioética, Brasília, v.13, n.1, p. 111-123, 2005.

(13) GARRAFA, Volnei; PORTO Dora. Intervention bioethics: epistemology for peripheral countries. Journal International de Bioéthique, Paris, v.19, p.87-102, 2008.

(14) MAXIMILIANO, Carlos. Hermenêutica e aplicação do direito. Rio de Janeiro: Forense, 1980. 
ao caso aqui estudado: a regulação estatal da publicidade de produtos sujeitos à vigilância sanitária. Serão utilizados como peças de estudo cinco diferentes produtos emblemáticos de consumo que já são regulados pelo Ministério da Saúde, via Anvisa.

O estudo tem como marco teórico a Bioética de Intervenção que, a partir de perspectiva utilitarista crítica e solidária, considera as relações sociais de produção e as inter-relações humanas que afetam a saúde dos vulneráveis, atribuindo ao Estado o papel de protetor dos interesses de indivíduos que se encontrem em tal condição.

\section{Cinco casos emblemáticos de intervenção estatal em publicidade}

No sentido de ilustrar os termos pelos quais a intervenção estatal em publicidade se dá no Brasil.

\subsection{Produtos Fumígeros}

O tabagismo é um dos problemas de saúde pública mais graves da contemporaneidade. Estima-se que aproximadamente cem milhões de pessoas morreram em decorrência da dependência da nicotina no século 20, e que pelo menos um bilhão poderá morrer em virtude de seu uso no século $21^{(15)}$.

Diante de fatos como este, a Anvisa determinou a inserção de imagens referentes aos malefícios do cigarro nas embalagens desses produtos, restringiu a publicidade apenas aos pontos de venda, e proibiu a comercialização de produtos alimentícios que simulassem derivados do tabaco, como os tradicionais chocolates em forma de cigarrilhas.

\subsection{Bebidas alcoólicas}

Estima-se que o mercado brasileiro de cerveja tenha faturado $\mathrm{R} \$ 22$ bilhões no ano de 2006. O investimento do setor em publicidade superou $\mathrm{R} \$$ 704 milhões, sendo que $89 \%$ desse total foram destinados à publicidade em televisão. Por ter uma graduação alcoólica menor que $13^{\circ} \mathrm{GL}$, a publicidade

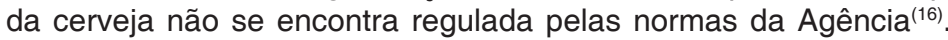

(15) PETO, Richard; LOPEZ, Alan D. Future worldwide health effects of current smoking patterns. In: KOOP, C. Everett; PEARSON Clarence E.; Schwarz M. Roy (Eds.). Critical issues in global health. Jossey-Bass, 2001. p. 154-161.

(16) ANVISA restringirá propaganda de cerveja. Disponível em: <http://portal.prefeitura.sp.gov.br/ noticias/sec/participacao_parceria/comuda/0201>. 
Segundo normativas da Anvisa, a propaganda comercial de bebidas com teor alcoólico superior a 13 (GL) somente poderá ser veiculada no rádio e na televisão entre 21 h e 6 h; além de não poder associar o produto a práticas esportivas e a imagens e ideias de benefício social ou sexual.

Fundamentada em dados científicos e programas de saúde pública, a Anvisa manifestou-se no sentido de alterar a definição de bebida alcoólica estabelecida pela Lei n. 9.294/96. Todavia, um Parecer da Consultoria-Geral da União constatou que a Agência, embora dotada de incontestável poder normativo, não poderia, por meio de Resolução da Diretoria Colegiada (RDC), alterar um conteúdo de lei ordinária ${ }^{(17)}$.

\subsection{Medicamentos}

Para fins de intervenção estatal na publicidade, deve-se diferenciar a publicidade de medicamentos voltados para o público leigo e a publicidade voltada aos profissionais da saúde.

Quanto à publicidade voltada ao público não leigo, Fagundes e colaboradores $^{(18)}$ demonstraram que é possível aos médicos prescreverem medicamentos influenciados pela publicidade e por brindes e prêmios, como o patrocínio para a participação em congressos, cursos e eventos. Quanto à publicidade voltada ao público leigo, conforme estudo realizado em $2005^{(19)}$, a indústria farmacêutica ressalta em sua veiculação os aspectos positivos em detrimento dos possíveis riscos e contraindicações. Além disso, utiliza apresentadores, artistas e atletas famosos, atraindo, por meio da identificação, um consumo de necessidades criadas artificialmente.

A previsão de regulamento específico para a publicidade de medicamentos foi prevista na Constituição de 1998. Entretanto, antes mesmo da Constituinte de 1988, a Lei n. 6.360/76 (que dispõe sobre vigilância sanitária a que ficam sujeitos os medicamentos, as drogas e os insumos farmacêuticos e correlatos, cosméticos, saneantes e outros produtos) e o Decreto n. 79.094/77 (que regulamenta a Lei n. 6.360/76), já regulamentavam de forma bastante específica a publicidade e a propaganda de medicamentos no Brasil. Ambos os estatutos foram historicamente desconsiderados pelo setor regulado (indústria, meios de comunicação, agências de publicidade e mercado varejista de medicamentos), mas apenas em 2000, após a criação da Anvisa,

(17) BRASIL. Nota Advocacia-Geral da União - 16/2007. Disponível em: <http://www.agu.gov.br/ upload/docs/spc/INTER_BRASILIA/Nota\%20GV-16-2007\%20-\%201\%20-\%20Inteiro\%20Teor.pdf>.

(18) FAGUNDES, Maria José Delgado; SOARES, Magnely Gomes Alves; DINIZ Nilza Maria; PIRES Jansen Ribeiro; GARRAFA Volnei. Análise bioética da propaganda e da publicidade de medicamentos. Ciência \& Saúde Coletiva, Rio de Janeiro, v. 12, n. 1, p. 221-229, 2007.

(19) NASCIMENTO, Alvaro Cesar; SAYD, Jane Dutra. Ao persistirem os sintomas o médico será consultado: Isto é regulação? Physis, Rio de Janeiro, v. 15, n. 2, p. 305-328, 2005. 
é que tal regulamento foi editado e aplicado às mensagens publicitárias. $\mathrm{O}$ objetivo foi o de reduzir a exposição da população à propaganda abusiva e enganosa, e abordar questões de saúde coletiva como a automedicação, intoxicações e uso inadequado de medicamentos.

\subsection{Alimentos em geral}

Estudo recente apontou que a maioria dos anúncios dos produtos alimentícios analisados estava no grupo da pirâmide alimentar representado por gorduras, óleos, açúcares e doces. O segundo maior grupo constituiu-se por pães, cereais, arroz e massas. Conforme os autores ${ }^{(20)}$, a pirâmide construída a partir da frequência de veiculação de alimentos na TV difere significativamente da pirâmide considerada ideal por nutricionistas.

Outro estudo revelou que muitas indústrias e cadeias de restaurantes retiraram ou minimizaram a quantidade de ácidos graxos trans dos seus produtos, alegando na publicidade $0 \%$ de gordura como uma medida boa para saúde. Entretanto, o que não dizem é que, em substituição à gordura trans, utilizam outras gorduras saturadas com mesmo potencial deletério para a saúde(21).

Em decorrência das doenças nutricionais e com vistas a uma alimentação saudável, a Anvisa publicou em 2001 uma RDC que estabelece a obrigatoriedade de rotulagem nutricional de alimentos e bebidas embalados. Entre 2006 e 2007, a Agência, por meio de consulta pública, propôs regulamentar a publicidade de alimentos com elevado teor de açúcar, sódio e gorduras saturadas e trans, bem como de bebidas com baixo teor nutricional.

Antevendo a pressão estatal sobre a publicidade de produtos que contêm gordura trans, o setor regulado antecipou-se às decisões e promoveu alterações nos produtos.

\subsection{Alimentos para crianças}

O IBGE informa que, nos últimos 30 anos, houve expressivo aumento no número de crianças e adolescentes acima do peso. Dados do Sistema de Informação sobre Mortalidade do Ministério da Saúde ${ }^{(22)}$ indicam que doenças

(20) ALMEIDA, Sebastião de Sousa; NASCIMENTO, Paula Carolina B. D.; QUAIOT, Tereza Cristina Bolzan. Quantidade e qualidade de produtos alimentícios anunciados na televisão brasileira. Revista de Saúde Pública, São Paulo, v. 36, n. 3, p. 353.355, 2002.

(21) GAGLIARDI, Ana Carolina Moron; MANCINI FILHO, Jorge; SANTOS, Raul D. Perfil nutricional de alimentos com alegação de zero gordura trans. Revista da Associação Médica Brasileira, São Paulo, v. 55 , n. 1, p.50-53, 2009. 
como diabetes, obesidade e infarto são responsáveis por quase $50 \%$ das mortes no Brasil e representam atualmente $69 \%$ dos gastos do SUS.

Seguindo normas da Organização Mundial da Saúde e do Unicef, o Ministério da Saúde, desde 1992, vem publicando diretrizes sobre a promoção de práticas saudáveis relacionadas à alimentação de crianças na primeira infância. Nesse sentido, caberia à Anvisa proibir fotos e desenhos que não sejam referentes à ilustração dos métodos de preparação ou uso do produto, de modo a minimizar a indução de alimentos não saudáveis entre a faixa etária. Personagens infantis, figuras de frutas, legumes, animais, ou flores seriam restringidos na divulgação e promoção do produto.

\section{O Manifesto do Conar}

No Brasil, cabe ao Conar, organização não governamental, "impedir que a publicidade enganosa ou abusiva cause constrangimento ao consumidor ou a empresas". A entidade é responsável por aplicar o Código Brasileiro de Auto-Regulamentação Publicitária, norma de caráter privado, destinada à solução de demandas que envolvem denúncias de consumidores, autoridades, associados ou integrantes do Conselho.

O referido Código nasceu como reação à tentativa do governo militar do Brasil sancionar lei, criando censura prévia à publicidade, tendo, portanto, sido redigido em claro contexto de luta pela garantia do direito fundamental à liberdade de livre manifestação do pensamento(23). Dessa forma, embora o código também zele pelos direitos e interesses da coletividade representada pela figura do consumidor, seu escopo, definido por sua origem histórica, é fundamentalmente direcionado à defesa dos interesses dos anunciantes, agências de publicidade e veículos de comunicação(24).

Por isso, não obstante o esforço das entidades signatárias do referido Código, no sentido de determinar parâmetros éticos para a prática publicitária, a intrínseca vulnerabilidade do consumidor não admite que a regulação desses anúncios se dê por meio de exclusiva autorregulamentação do setor, principalmente quando, em sua missão, o Conar não prevê a saúde da população como um dos princípios norteadores da atividade publicitária.

Recentemente, depois de a Anvisa publicar uma Resolução da Diretoria Colegiada (RDC) que alterava a definição de bebida alcoólica, passando a considerar como tal toda aquela com graduação superior a 0,5 GL, a fim de

(22) ANVISA quer regular publicidade de alimentos "não saudáveis". Disponível em: <http:// www.indecs.org.br/index2.php?option=com_content\&do_pdf=1\&id=116>.

(23) PAULA, Eliane Silva de. Publicidade e controle social: o papel do Conselho Nacional de AutoRegulamentação Publicitária. Dissertação (Mestrado) - Brasília: Universidade de Brasília, 2005.

(24) LARANJEIRA, Ronaldo; ROMANO Marcos. Brazilian consensus on public policies on alcohol. Revista Brasileira de Psiquiatria, São Paulo, v. 26, supl. 1, p. 68-77, 2004. 
poder regular sobre a publicidade de cervejas, o Conar e mais dez entidades ligadas ao setor decidiram lançar um manifesto com relação à regulamentação da propaganda, endereçado às autoridades e ao mercado publicitário, afirmando que a Anvisa não seria competente para legislar sobre publicidade, pois, conforme a Constituição Federal determina, esta função compete privativamente à União(25).

\section{HERMENÊUTICA LEGISLATIVA SOBRE O TEMA}

Como foi apresentada anteriormente, a hermenêutica legislativa consiste em interpretar o ordenamento jurídico - conjunto das leis vigentes em um país, ordenadas segundo critérios hierárquicos — de modo a relacioná-lo a um caso concreto.

Em virtude da complexidade das organizações sociais, e para que se discutam com propriedade os conflitos de interesse envolvendo as formas de intervenção na publicidade anteriormente enumeradas, faz-se necessário abordar os seguintes referenciais afetos ao tema: liberdade de expressão, função social da propriedade, direito à saúde, e direito do consumidor.

\section{Liberdade de expressão}

A manifestação do pensamento constitui o exercício da liberdade de opinião, e a possibilidade de os seres humanos construírem seus consensos e gerenciarem o poder está bem desenvolvido na "ética do discurso" e no "agir comunicativo" trabalhados por Habermas ${ }^{(26)}$.

Uma das formas mais comuns de manifestação do pensamento humano se dá por meio da publicidade, que divulga informações para promover vendas de bens e serviços. Numa democracia recente como a brasileira, historicamente antecedida por flagrantes abusos estatais contrários à livre manifestação da opinião e do pensamento, a expressa defesa desse direito fundamental faz-se imprescindível, de tal sorte que a Constituição Federal o garante.

Também no intuito de assegurar a chamada liberdade de expressão, a Constituição assevera que a manifestação do pensamento, a criação, a expressão e a informação, sob qualquer forma, não sofrerão restrição, e estabelece como absolutamente livre qualquer manifestação do pensamento humano. Todavia, análise mais criteriosa do referido texto legal não deixa

(25) CONAR. Disponível em: <http://www.conar.org.br/html/noticias/anvisa.htm>.

(26) HABERMAS, Jürgen. Consciência moral e agir comunicativo. 2. ed. Rio de Janeiro: Tempo Brasileiro, 2003. 240 p. 
dúvidas da subsequente relativização daquilo que, a princípio, se postulou como absoluto: a manifestação do pensamento, sob qualquer forma, não sofrerá qualquer restrição (assertiva em termos absolutos), seguida, nos parágrafos subsequentes, por assertivas de caráter relativo: informação de natureza jornalística e vedação a toda e qualquer censura de natureza política, ideológica e artística ${ }^{(27)}$.

O texto constitucional prevê modalidades de clara limitação ao direito de livre manifestação do pensamento, quando determina que compete à lei federal estabelecer os meios legais que garantam à pessoa e à família a possibilidade de se defenderem da propaganda de produtos, práticas e serviços que possam ser nocivos à saúde e ao meio ambiente.

Diante do exposto, fica claro que, embora prima facie a proteção ao direito de livre manifestação do pensamento pareça se dar em termos absolutos, o fato de o legislador constitucional não ter incluído a modalidade publicitária nas hipóteses expressas de manifestação livre do pensamento, somado à explícita restrição à publicidade de produtos que possam ser nocivos à saúde, não deixa lacunas para questionamentos quanto aos limites impostos a esse tipo de produção intelectiva.

No mais, não bastasse a expressa determinação legislativa no sentido de regular a publicidade de produtos que possam ser nocivos à saúde, compete destacar que a manifestação publicitária, por suas características intimamente relacionadas ao instituto da propriedade privada, não deve, em decorrência da função social da propriedade, sobrepujar o interesse coletivo.

\section{Função social da propriedade}

Por se tratar, o Brasil, de um Estado Democrático de Direito, o mesmo dispositivo constitucional que afirma ser "garantido o direito de propriedade" determina, também, limites e formas para o exercício desse direito.

No caso de bens, cuja relação de propriedade repercuta sobre toda a coletividade, a proteção dessa relação estará condicionada à observação de algumas condições consubstanciadas na chamada função social da propriedade. Desse modo, no que se refere a esses bens, somente relações que preencham condições determinadas pelo ordenamento jurídico serão passíveis de proteção pelo instituto do direito de propriedade. No caso da indústria de bens sujeitos à vigilância sanitária, a proteção estatal ao direito de propriedade só se legitima na medida em que o uso da tecnologia,

(27) BRASIL. Constituição da República, arts. $5^{\circ}$ incisos IV, V, IX, X, XIV e LX, $1^{\circ}$ e 2ํㅜㄴ Lei n. 5.250, de 09 de fevereiro de 1967. 
desenvolvida a partir dos investimentos em pesquisa, atenda aos interesses da sociedade, na qual esses mesmos bens serão comercializados e, portanto, anunciados, excluindo-se modos de apropriação que afrontem os interesses e o bem-estar da coletividade.

\section{Dignidade humana}

A garantia da relação de propriedade privada é reconhecida no ordenamento jurídico, tendo o legislador constitucional atribuído a esse instituto, em associação ao cumprimento de sua função social, o status de mantenedor da atividade econômica, de modo a garantir existência digna a todos os cidadãos.

Para Neri(28), o conceito filosófico de dignidade humana, embora sustente muitas concepções, constituir-se-ia de uma intuição moral fundamental, que une dignidade e respeito. Mas, na prática, essa articulação é muito complicada, daí a substituição, muitas vezes, de dignidade humana pelo conceito de natureza, como aquilo que se considera certo ou bom e, a partir desse conceito, tentar-se deduzir prescrições e proibições.

$K a n t^{(29)}$ foi o primeiro teórico a reconhecer que ao homem não se pode atribuir valor, na medida em que deve ser considerado como um fim em si mesmo, em função da sua autonomia enquanto ser racional, e jamais como instrumento para satisfazer os interesses de outrem. Para ele, a dignidade é uma qualidade inerente aos seres humanos como entes morais e é inseparável da autonomia para o exercício da razão prática. Todo ser racional, como fim em si mesmo, possui um valor não relativo, mas intrínseco; e a dignidade de um ser racional consiste no imperativo categórico de ele não obedecer a nenhuma lei que não seja, também, instituída por ele mesmo.

Ao lado da tradicional concepção judaico-cristã que concebe o ser humano como especial imago dei, um dos fundamentos teóricos da dignidade humana mais aceitos se volta àquela autonomia racional do ser humano. Entretanto, nos dias de hoje, a concretização da dignidade não pode limitar-se exclusivamente à autonomia racional, pois não se admite, sob hipótese alguma, que o ser humano seja tratado como coisa. A dignidade se efetiva na alteridade, na relação com o outro e, em contextos de desigualdade social em que as relações assimétricas se caracterizam pela vulnerabilidade, a responsabilidade moral exige tratar o outro com dignidade.

(28) NERI, Demétrio. Questões filosóficas na pesquisa e uso de células-tronco. Uma perspectiva européia. In: GARRAFA, Volnei, PESSINI, Leo (Eds.). Bioética: poder e injustiça. 2. ed. São Paulo: Loyola, 2004. 522 p.

(29) KANT, Immanuel. Fundamentação da metafísica dos costumes e outros escritos. São Paulo: Martin Claret, 2004. 150 p. 
O conceito de dignidade humana é um dos valores a serem assegurados pela ordem econômica nacional, bem como pelo setor privado. O ordenamento jurídico impõe aos titulares de bens de produção condutas socialmente responsáveis, com intuito de obter o ideal da dignidade humana.

Ainda acerca do conceito de dignidade humana, cabe frisar que a Declaração Universal sobre Bioética e Direitos Humanos da UNESCO(30) contempla esse conceito como fundamento teórico-normativo, assim como o faz a Constituição Federal.

\section{Direito à saúde}

Conforme anteriormente mencionado, a Constituição Federal garante a inviolabilidade do direito à vida. Além disso, prevê, como dever do Estado, a garantia do direito à saúde de todos os cidadãos.

No que concerne à operacionalização desse direito, a Constituição Brasileira certifica a regulamentação dos serviços e ações em saúde e, a fim de disciplinar a forma como o Estado cumprirá esse dever, prevê que ao Sistema Único de Saúde compete, além de outras atribuições, nos termos da lei, controlar e fiscalizar procedimentos, produtos e substâncias de interesse para a saúde.

\section{Defesa do consumidor}

A Constituição Federal de 1988 garante que o Estado promoverá, na forma da lei, a defesa do consumidor e, nesse sentido, promulgou-se o Código de Defesa do Consumidor (CDC), que estabelece a vulnerabilidade como princípio norteador da Política Nacional das Relações de Consumo. Ao determinar como direitos básicos do consumidor "a proteção da vida, saúde, e segurança, contra os riscos provocados por práticas no fornecimento de produtos e serviços considerados perigosos ou nocivos", estabelece os direitos do consumidor como ferramenta para a proteção da saúde.

Além disso, o CDC estabelece como abusiva a publicidade que se aproveite da deficiência de julgamento e experiência ou que seja capaz de induzir o consumidor a se comportar de forma prejudicial ou perigosa à sua saúde e segurança, vai além quando trata de "publicidade enganosa", tal como explicitado nos arts. 4 e 37 :

(30) UNESCO. Declaração Universal de Bioética e Direitos Humanos. Adotada por aclamação em 19 de outubro de 2005 pela 33a Sessão da Conferência Geral da UNESCO. Tradução e revisão final sob a responsabilidade da Cátedra UNESCO de Bioética da Universidade de Brasília (UnB) e da Sociedade Brasileira de Bioética (SBB). Disponível em: <www.bioetica.catedraunesco.unb.br>. 
Art. 4 - Estabelece o princípio da transparência, pelo qual o consumidor tem o direito à informação adequada, clara, certa e completa sobre os produtos e serviços, para escolhê-los bem, sabendo com exatidão o que poderá esperar deles, ao adquiri-los.

Art. 37. Reconhece o direito do consumidor de não ser enganado por qualquer informação inteira ou parcialmente falsa ou fraudulenta, capaz de, por ação ou omissão, induzi-lo em erro a respeito da natureza, características, qualidade, quantidade, propriedades, origem, preço e quaisquer outros dados sobre produtos e serviços.

Desse modo, um dos princípios de crucial relevância, no qual se sustenta o CDC, é o conceito de vulnerabilidade, também contemplado pela Declaração de Bioética da UNESCO acima referida.

O Código assevera que a vulnerabilidade é um traço inerente a todo e qualquer consumidor, independentemente de sua situação educacional, econômica ou cultural. Tal princípio constitui a essência da proteção ao consumidor, uma vez que, na relação de consumo, há subordinação do sujeito pelo fornecedor ${ }^{(31)}$.

Por existir natural desvantagem em toda relação de consumo, existe também forte justificativa ética que aponta a necessidade de intervenção em favor dos potencialmente prejudicados. Para Siqueira ${ }^{(32)}$, a vulnerabilidade em um processo social complexo deve ser analisada não apenas a partir da subjetividade individual dos membros, mas também da própria subjetividade social que está constituída em diferentes níveis e momentos da organização. Segundo ele, nesta perspectiva, a bioética defende o reconhecimento pleno da cidadania a todos os seres humanos, em especial aos mais vulneráveis. A bioética brasileira e a latino-americana não apenas reproduzem tal discurso, como o defendem a partir da constatação da realidade social assimétrica e injusta para uma grande maioria.

\section{A AUTONOMIA E A CRIANÇA}

Para Piaget ${ }^{(33)}$, a gênese da razão, da afetividade e da moral se constrói progressivamente. No início, a criança vive no mundo pré-moral e não tem condições de aceitar as regras de convívio social. Aos poucos, torna-se heterônoma, aceita as regras exteriores, integrando as normas da família e da sociedade. Na adolescência, desenvolve a capacidade de reflexão e

(31) CABRAL, André Luiz Cavalcante. Aspectos jurídicos da publicidade. Prim @ Facie, João Pessoa, ano 2, n. 2, p. 129-144, 2003. Disponível em: <http://www.ccj.ufpb.br/primafacie>.

(32) SIQUEIRA, José Eduardo. Ensaio sobre a vulnerabilidade humana. Revista Brasileira de Bioética, Brasília, v. 2, n. 2, p. 220-236, 2006.

(33) PIAGET, Jean. Seis Estudos de psicologia. 24. ed. Rio de Janeiro: Forense, 2003. 136 p. 
começa a perceber as limitações impostas, bem como a necessidade de orientar suas ações, superar os condicionamentos e se autodeterminar. Segundo Kolbergh (apud Biaggio)(34), é apenas na idade adulta que o indivíduo percebe o conflito entre as leis exteriores e a conquista da autonomia, embora talvez nunca encontre uma autonomia absoluta. Na definição de Perrenoud $^{(35)}$, a autonomia do sujeito é caracterizada pela competência em mobilizar um conjunto de recursos cognitivos para solucionar, com pertinência e eficácia, os problemas de sua realidade.

$\mathrm{Na}$ implementação de políticas públicas para proteção de crianças e adolescentes, o Estatuto da Criança e do Adolescente (ECA) parte do pressuposto de que as crianças não têm autonomia e, portanto, são vulneráveis também em suas condições de consumidores, dependendo, portanto, da especial atenção e tutela do Estado.

\section{DISCUSSÃO}

Conforme anteriormente esclarecido, embora a liberdade de expressão, no que concerne à manifestação publicitária do pensamento, prima facie, esteja protegida em termos absolutos, na verdade, tal liberdade encontra-se regulada pelo Estado. No mais, ainda que se levassem em consideração os argumentos que afirmam que a inclusão da liberdade de expressão entre os direitos fundamentais arrolados na Constituição confere a estes o status de direitos invioláveis, a correta interpretação da dogmática jurídica seria que, não obstante fundamentais, tais direitos não se revestem do caráter absoluto que a eles o setor publicitário pretende conferir.

A realidade é que a melhor hermenêutica da Constituição Federal condiciona o direito à livre manifestação do pensamento à consecução do princípio da dignidade humana, corolário intrínseco ao texto constitucional. Qualquer direito fundamental constante do texto constitucional só se pode perfazer, na medida em que o princípio da dignidade da pessoa humana não seja por ele afetado, condicionando-se, portanto, a observação dos direitos fundamentais - incluído o direito à livre manifestação do pensamento — à inviolabilidade do direito à vida.

Em que pese o direito à livre manifestação do pensamento, a publicidade tem sua origem na relação de propriedade, a qual, no ordenamento brasileiro, é condicionada pelo cumprimento de sua função social. Ora, se a

(34) BIAGGIO, Ângela Maria Brasil. Lawrence Kohlberg: ética e educação moral. 2. ed. São Paulo: Ed. Moderna, 2006. 127 p.

(35) PERRENOUD, Phillipe; THURLER, Monica Gather. Competências para ensinar no século XXI. 1. ed. Porto Alegre: ArtMed, 2002. 176 p. 
relação de propriedade em si é relativizada no que concerne à natureza do objeto e forma de exploração, por que a divulgação publicitária dos objetos dessa exploração deveria ser garantida em termos absolutos?

O Código Defesa do Consumidor deixa claro que a liberdade de criação publicitária, no Brasil, não é um direito absoluto, haja vista que essa modalidade de manifestação do pensamento humano tem de respeitar o consumidor a que se destina, de modo a, mediatamente, respeitar os interesses coletivos da sociedade na qual se insere.

Além disso, é importante ressaltar que a defesa absoluta do direito de manifestação do pensamento somente se justifica como tal, por se tratar de mecanismo de defesa dos interesses do indivíduo, presumidamente vulnerável, perante o poderio estatal que, a fim de perpetuar seu status, pode vir a se valer da força para que prevaleçam sua ideologia e discurso, em detrimento de outros interesses. Tal presunção, logicamente, não se aplica à realidade dos anunciantes de produtos sujeitos à vigilância sanitária, haja vista que, nos casos em que um produto possa vir a interferir na saúde do indivíduo, a parte vulnerável da relação comercial será o consumidor.

Diante de toda argumentação já exposta, o presente estudo contesta a alegação do Conar relativa ao fato de que a Anvisa não seria legítima para legislar sobre propaganda e publicidade de produtos sujeitos à vigilância sanitária pelos motivos seguintes: a) além de haver explícito fundamento constitucional para a atuação da Anvisa, conforme se demonstrará, a Agência é normativamente competente para regulamentar a publicidade de produtos submetidos ao regime de vigilância sanitária; b) o referido manifesto, por meio de questionamento da legalidade das ações da Anvisa, pretende, na verdade, colocar em discussão não o princípio da legalidade (competência) dos atos da Agência, mas sua legitimidade, como se legalidade e legitimidade fossem conceitos jurídicos equivalentes e intercambiáveis.

\section{COMPETÊNCIA DA ANVISA}

"Competência é a faculdade juridicamente atribuída a uma entidade ou a um órgão ou agente do Poder Público para emitir decisões." (36) $E$, além disso, é o meio pelo qual se confere à entidade o dever de agir, os poderes para agir e os limites da sua atuação.

No Brasil, a Anvisa é um órgão do Poder Executivo dotado de competência normativa, uma vez que a Lei n. 9.782/99 determina que compete à União, no âmbito do Sistema Nacional de Vigilância Sanitária, normatizar,

(36) SILVA, José Afonso. Aplicabilidade das normas constitucionais. 7. ed. São Paulo: Malheiros Ed., 2007. 320 p. 
controlar e fiscalizar produtos, substâncias e serviços de interesse para a saúde, bem como atuar como entidade administrativa independente. Ora, se compete à Agência, de acordo com a lei, promover a proteção da saúde da população, por intermédio do controle sanitário da produção e da comercialização de produtos e serviços submetidos à vigilância sanitária, e se o exercício dessa proteção tem, como pressuposto, (...) regulamentar, controlar e fiscalizar os produtos e serviços que envolvam risco à saúde pública", então é obviamente legítima a pretensão de que a Anvisa venha a controlar, fiscalizar e acompanhar, a partir do prisma da legislação sanitária, a propaganda e publicidade de produtos submetidos ao regime de vigilância sanitária.

\section{Legitimidade da atuação da Anvisa}

Na hipótese, já descartada por este estudo, de que a atuação da Anvisa não fosse legal, por incompetência da Agência para a regulação de publicidade de produtos sujeitos à vigilância sanitária, a intervenção estatal nesse métier, ainda assim, seria legítima, haja vista o fato de sua justificação emanar da defesa dos interesses coletivos relacionados ao direito à saúde e à defesa do consumidor e da criança.

A confusão deliberadamente criada por manifestações como essa, divulgada pelo Conar, entre os conceitos de "legalidade" e "legitimidade", reduz a questão à interpretação estritamente lógico-formal da dogmática jurídica, sem levar em consideração os interesses coletivos que a permeiam, justificando a atuação regulatória do Estado, por intermédio de sua Agência competente.

Nesse sentido, “... é indispensável, para que se reconheça e se mantenha a legitimidade, que haja convergência das aspirações do grupo e dos objetivos do poder". Legitimidade é uma qualidade do poder, e a legalidade refere-se ao exercício do mesmo; por isso, Dallari ${ }^{(37)}$ afirma que poder legítimo é o poder consentido.

Tendo em vista que o poder se legitima por meio do consentimento social e, uma vez que a atuação regulatória da Anvisa é desdobramento necessário de suas atuações no sentido de garantir, no país, a proteção e a promoção à saúde, não há por que existir dúvidas a respeito da legitimidade dessas ações, dado que correspondem às aspirações mais intrinsecamente relacionadas ao corpo social.

A respeito do disposto na Constituição Federal, que estabelece restrições legais à publicidade de produtos sujeitos à vigilância sanitária, a

(37) DALLARI, Dalmo de Abreu. Elementos de teoria geral do Estado. 27. ed. São Paulo: Saraiva, 2007. 312 p. 
melhor hermenêutica se dá por meio de interpretação teleológica do texto, segundo a qual o legislador não buscou fornecer lista exaustiva de situações nas quais cumprirá ao Estado restringir a publicidade (tabaco, bebidas alcoólicas, agrotóxicos, medicamentos e terapias), mas que, ao contrário, trata-se de lista exemplificativa de produtos potencialmente deletérios à saúde humana.

\section{O CONTEXTO E A BIOÉTICA DE INTERVENÇÃO}

O referencial teórico empregado no presente estudo - A Bioética de Intervenção - é considerado uma perspectiva epistemológica anti-hegemônica dentro dos estudos da bioética, majoritariamente focados na crítica à corrente teórica estadunidense conhecida como "principialismo".

Formalmente apresentada à comunidade internacional no Sexto Congresso Mundial de Bioética, em 2002, a Bl justifica-se como um arcabouço teórico adaptado às análises de macroproblemas éticos e conflitos coletivos ocorridos especialmente nos países periféricos (países pobres ou em desenvolvimento).

Ao contrário do arcabouço principialista - direcionado exclusivamente às questões biomédicas e biotecnológicas - a BI incorpora temas sociais, sanitários e ambientais a serem analisados a partir de uma perspectiva utilitarista, crítica e solidária comprometida com os grupos historicamente mais vulneráveis de cada contexto.

Como a BI atribui ao Estado a responsabilidade por garantir a proteção dos direitos individuais e coletivos da população, pode-se afirmar que o referencial teórico empregado no presente estudo justifica eticamente a intervenção do Estado na publicidade de alimentos sujeitos à vigilância sanitária.

\section{CONSIDERAÇÕES FINAIS}

O Conar tem, reiteradamente, afirmado que a atuação da Anvisa ultrapassaria seu campo legal de atuação e que caberia exclusivamente ao Congresso Nacional o estabelecimento, por Lei, de regulação à publicidade e à propaganda. No entanto, essa alegação é refutada, na medida em que a atuação da Agência, pautada nos princípios da segurança jurídica, da legalidade, da igualdade e da impessoalidade, se sustenta no conjunto das normas legais vigentes.

Ademais, a partir da demonstração de que o direito à livre manifestação do pensamento subordina-se à observação do princípio da dignidade humana e do direito à saúde, o presente estudo contesta o argumento, defendido pelo Conar, de que a intervenção estatal em publicidade de produtos sujeitos à vigilância sanitária não é legítima ou legal. 
A forma como os produtos sujeitos à vigilância sanitária serão anunciados ao público subordina-se ao princípio da função social da propriedade, segundo o qual é vedado ao proprietário explorar esses bens em prejuízo da coletividade. Por isso, quando a publicidade de certos produtos comerciais apresentar-se potencialmente nociva à saúde dos consumidores, o Conar não poderá prescindir da intervenção estatal.

Por desconhecer a legitimidade e a competência da Anvisa, senão mesmo por reproduzir a ideologia do mercado de consumo, o Conar tenta descaracterizar a Agência em seu manifesto, para que particulares, por meio de publicidade contrária aos interesses coletivos, aufiram lucro em detrimento da saúde da população. Cabe considerar ainda que ao classificar como censura a regulação e controle com vistas a proteger e promover a saúde da população realizado pela Anvisa, o Conar busca por artifício de retórica identificar a atuação legítima e legal da Agência com as estratégias repressivas dos regimes totalitários, desconsiderando, dessa forma, a finalidade última dessa intervenção que é o bem comum naquilo que há de mais valioso ao cidadão e à coletividade: a saúde.

Constata-se que, embora o Estado procure fiscalizar e regulamentar os alimentos que possam representar riscos à saúde, o mercado tenta encontrar saídas nem sempre favoráveis ao consumidor, o que, mais uma vez, legitima a intervenção neste setor.

$\mathrm{Na}$ defesa da justiça social, o marco teórico referencial deste trabalho, a "Bioética de Intervenção", segundo a qual "as decisões mais justas são aquelas que beneficiam o maior número de pessoas, pelo maior espaço de tempo, resultando nas melhores consequências coletivas"(11), ou seja, defende e justifica ações de políticas públicas utilitaristas, consequencialistas e solidárias, com atenção especial aos mais vulneráveis. O Estado é apontando como o responsável perante os cidadãos e deve intervir sempre, para que seja garantida e preservada a dignidade e integridade da população. Essa é uma lógica equitativa que procura minimizar as assimetrias das relações sociais e econômicas para que se amenizem, no fim, os efeitos deletérios da vulnerabilidade.

Por fim, certos de que a intervenção da Anvisa se sustenta no conjunto das normas legais vigentes, não consiste em censura prévia e protege os interesses da coletividade, sua atuação é legítima e necessária para a proteção da sociedade.

\section{REFERÊNCIAS BIBLIOGRÁFICAS}

ABA, ABAP, ABERT, ABTA, ANER, ANJ, CENTRAL DE OUTDOOR, FENAPRO, FENEEC, IAB Anvisa não é competente para legislar sobre publicidade. Disponível em: <http://www.conar.org.br/html/noticias/anvisa.htm>. 
ALMEIDA, Sebastião de Sousa; NASCIMENTO, Paula Carolina B. D.; QUAIOT, Tereza Cristina Bolzan. Quantidade e qualidade de produtos alimentícios anunciados na televisão brasileira. Revista de Saúde Pública, São Paulo, v. 36, n. 3, p. 353:355, 2002.

ANVISA quer regular publicidade de alimentos "não saudáveis". Disponível em: $<$ http://www.indecs.org.br/index2.php?option=com_content\&do_pdf=1\&id=116>.

ANVISA restringirá propaganda de cerveja. Disponível em: <http:// portal.prefeitura.sp.gov.br/noticias/sec/participacao_parceria/comuda/0201>.

BAUDRILLARD, JEAN. A sociedade do consumo. 2. ed. Lisboa: Edições 70, 2007. 216 p.

BAUMAN, Zygmunt. [Artigo publicado no jornal] La Repubblica, 16 set. 2007.

BIAGGIO, Ângela Maria Brasil. Lawrence Kohlberg: ética e educação moral. 2. ed. São Paulo: Ed. Moderna, 2006. 127 p.

BRASIL. Nota Advocacia Geral da União - 16/2007. Disponível em: <http:// www.agu.gov.br/upload/docs/spc/INTER_BRASILIA/Nota\%20GV-162007\%20-\%201\%20-\%20Inteiro\%20Teor.pdf>.

CABRAL, André Luiz Cavalcante. Aspectos jurídicos da publicidade. Prim@ Facie, João Pessoa, ano 2, n. 2, p. 129-144, 2003. Disponível em: <http:// www.ccj.ufpb.br/primafacie>.

CIENTISTAS põem anúncios em xeque. São Paulo, Valor Econômico, São Paulo, 20 jan. 2007. p. B5.

CONAR. Código Nacional de Auto-regulamentação Publicitária. Disponível em: <http://www.conar.org.br/html/codigos/todos\%20os\%20capitulos.htm>.

Disponível em: <http://www.conar.org.br/html/noticias/anvisa.htm>.

DALLARI, Dalmo de Abreu. Elementos de teoria geral do Estado. 27. ed. São Paulo: Saraiva, 2007. 312 p.

EAGLETON, Terry. Ideologia: uma introdução. São Paulo: UNESP, 1997. 204 p.

FAGUNDES, Maria José Delgado; SOARES, Magnely Gomes Alves; DINIZ Nilza Maria, PIRES Jansen Ribeiro; GARRAFA Volnei. Análise bioética da propaganda e da publicidade de medicamentos. Ciência \& Saúde Coletiva, Rio de Janeiro, v. 12, n. 1, p. 221-229, 2007.

GAGLIARDI, Ana Carolina Moron; MANCINI FILHO, Jorge; SANTOS, Raul D. Perfil nutricional de alimentos com alegação de zero gordura trans. Revista da Associação Médica Brasileira, São Paulo, v. 55, n. 1, p.50-53, 2009.

GARRAFA, Volnei; PORTO Dora. Intervention bioethics: epistemology for peripheral countries. Journal International de Bioéthique, Paris, v. 19, p. 87102, 2008. 
Intervention bioethics: a proposal for peripheral countries in a context f power and injustice. Bioethics, Diliman, v. 17, n. 5-6, p. 399-415, 2003.

HABERMAS, Jürgen. Consciência moral e agir comunicativo. 2. ed. Rio de Janeiro: Tempo Brasileiro; 2003. 240 p.

KANT, Immanuel. Fundamentação da metafísica dos costumes e outros escritos. São Paulo: Martin Claret, 2004. 150 p.

LARANJEIRA, Ronaldo; ROMANO Marcos. Brazilian consensus on public policies on alcohol. Revista Brasileira de Psiquiatria, São Paulo, v. 26, supl. 1, p. 68-77, 2004.

MAXIMILIANO, Carlos. Hermenêutica e aplicação do direito. Rio de Janeiro: Forense, 1980.

NASCIMENTO, Alvaro Cesar; SAYD, Jane Dutra. Ao persistirem os sintomas o médico será consultado: Isto é regulação? Physis, Rio de Janeiro, v. 15, n. 2, p. 305-328, 2005.

NERI, Demétrio. Questões filosóficas na pesquisa e uso de células-tronco. Uma perspectiva européia. In: GARRAFA, Volnei, PESSINI, Leo (Eds.). Bioética: poder e injustiça. 2. ed. São Paulo: Loyola, 2004. 522 p.

PAULA, Eliane Silva de. Publicidade e controle social: o papel do Conselho Nacional de Auto-Regulamentação Publicitária. Dissertação (Mestrado) Brasília: Universidade de Brasília, 2005.

PERRENOUD, Phillipe; THURLER, Monica Gather. Competências para ensinar no século XXI. 1. ed. Porto Alegre: ArtMed, 2002. 176 p.

PETO, Richard; LOPEZ, Alan D. Future worldwide health effects of current smoking patterns. In: KOOP, C. Everett; PEARSON Clarence E.; Schwarz M. Roy (Eds.). Critical issues in global health. Jossey-Bass, 2001. p. 154-161.

PIAGET, Jean. Seis Estudos de psicologia. 24. ed. Rio de Janeiro: Forense, 2003. $136 \mathrm{p}$.

PORTO, Dora. Tecnologia \& ideologia: os dois lados da moeda que produz vulnerabilidade. Revista Brasileira de Bioética, Brasília, v. 2, n.1, p. 63-86, 2006.

PORTO, Dora; GARRAFA Volnei. Bioética de Intervenção: considerações sobre a economia de mercado. Bioética, Brasília, v.13, n.1, p. 111-123, 2005. 